九州大学学術情報リポジトリ

Kyushu University Institutional Repository

\title{
3D Visualization and Topographical Analysis in Turning of Hybrid MMC By CNC Lathe SPRINT 16TC Made of BATLIBOI
}

Ashish Kumar Srivastava

G L Bajaj Institute of Technology and Management, Greater Noida

Shashi Prakash Dwivedi

G L Bajaj Institute of Technology and Management, Greater Noida

Nagendra Kumar Maurya

G L Bajaj Institute of Technology and Management, Greater Noida

Maurya, Manish

Accurate Institute of Management and Technology, Greater Noida

https://doi.org/10.5109/4055217

出版情報：Evergreen. 7 (2)，pp.202-208，2020-06. 九州大学グリーンテクノロジー研究教育センター バージョン：

権利関係 : 


\title{
3D Visualization and Topographical Analysis in Turning of Hybrid MMC By CNC Lathe SPRINT 16TC Made of BATLIBOI
}

\author{
Ashish Kumar Srivastava ${ }^{1}$, Shashi Prakash Dwivedi ${ }^{1}$, Nagendra Kumar Maurya ${ }^{1}$, \\ Manish Maurya ${ }^{2 *}$
}

${ }^{1} \mathrm{G}$ L Bajaj Institute of Technology and Management, Greater Noida, India

${ }^{2}$ Accurate Institute of Management and Technology, Greater Noida, India

*Author to whom correspondence should be addressed:

E-mail: manishmaurya33@gmail.com

(Received December 21, 2019; Revised May 23, 2020; accepted May 29, 2020).

\begin{abstract}
The performance evaluations of any manufacturing materials are significantly affected by their quality of surface as well as mechanical and metallurgical properties. MMCs are preferable material for the automobile and aircraft industries due to its excellent properties such as lightweight, high strength to weight ratio and high wear resistance. However, the presence of hard reinforcement particles in the matrix alloy makes it difficult to machine, which leads to the microstructural variation and extent of the subsurface damage. In the present study, three different rotational speed (varies from $200 \mathrm{rpm}$ to $600 \mathrm{rpm}$ ) is used to turn the surface of previously in-house made hybrid MMC A359/2\% $\mathrm{B}_{4} \mathrm{C} / 2 \% \mathrm{Al}_{2} \mathrm{O}_{3}$ on CNC lathe SPRINT $16 \mathrm{TC}$ made by BATLIBOI. An attempt is made to examine the $3 \mathrm{D}$ surface visualization and generate the surface roughness report by Micro-Prof FRT optical profilometer, surface topographical by Olympus Lext OLS 3100 laser confocal microscope for surface characterization. The results reveal the smooth machined surface with surface roughness ranges between $1.5 \mu \mathrm{m}$ to $2.9 \mu \mathrm{m}$. The topographical images revealed a flat surface full of repetitive cutting marks parallel to each other and along the direction of cutting. There are no significant topographical differences are varying rotational speed.
\end{abstract}

Keywords: Aluminum alloy A359; Metal matrix composite; 3D Surface visualization; Surface topography; CNC turning

\section{Introduction}

In Today's world, metal matrix composites (MMCs) are one of a suitable choice of material for most of the engineering application ${ }^{1-4)}$. The tremendous properties like lightweight, anti-corrosion and improved mechanical and thermal properties increase its demand in the manufacturing industries ${ }^{5-8)}$. However, the behaviour under machinability is also an important way of characterization of MMCs. These are hard to cut materials possess high hardness ${ }^{9-11)}$. Due to high hardness and the presence of hard ceramic particle which is abrasive proves poor results in the machining of MMCs generating high tool wear ${ }^{12-13)}$. Hence the study still searches for better machining method for such materials. The common types of machining operations such as cutting, milling, drilling and turning can be applied on MMCs 14-15). In turning operation, conventional turning is widely used for most of the MMCs. The conventional turning of MMCs includes the turning via simple lathe or CNC lathe ${ }^{16)}$. The cutting operation includes the physical contact of the tool with the rotating workpiece, and the removal of material is done in the form of continuous or discontinuous chips 17-18). The mechanism of cutting is shown in Figure 1. There are several challenges involves in turning of MMCs like accuracy in dimensions, improved machining results like better surface finishing and high metal removal rate (MRR), improved surface characterization properties, high tool life as well as low-cost ${ }^{19-20)}$. Most of the tool materials like high-speed steels and ceramics cannot be effectively applied for the machining of such hard MMCs because of the rapid wear due to the presence of hard reinforcement particles ${ }^{21)}$. However, coated carbides tools can withstand the tool to wear for a short time of machining 22-23). Most of the authors have reported that polycrystalline diamond (PCD) tools can be applied for the MMCs because of the capability of valuable tool life ${ }^{24)}$. It is to be noted that PCD is harder than $\mathrm{SiC}, \mathrm{B} 4 \mathrm{C}$ or $\mathrm{Al}_{2} \mathrm{O}_{3}$ and it possesses a non-chemically reactive tendency with work material but the main disadvantage of PCD tool is its high cost due to 
the diamond particle bonded ${ }^{25)}$.

In the machining operation, the quality of the machined surface plays an important role in deciding the suitable machining process for a particular material. In the present study, three different rotational speed (varies from $200 \mathrm{rpm}$ to $600 \mathrm{rpm}$ ) is used to turn the surface of previously in-house made hybrid MMC $\mathrm{A} 359 / 2 \% \mathrm{~B}_{4} \mathrm{C} / 2 \% \mathrm{Al}_{2} \mathrm{O}_{3}$ on $\mathrm{CNC}$ lathe SPRINT $16 \mathrm{TC}$ made by BATLIBOI. An attempt is made to examine the 3D surface visualization and generate the surface roughness report by Micro-Prof FRT optical profilometer, surface topographical by Olympus Lext OLS 3100 laser confocal microscope for surface characterization.

\section{Experimental Details}

The material selected for the study purpose is previously in-house developed hybrid metal matrix composite A359/2\%B4C/2\%Al2O3 produced by electromagnetic stir casting process. After testing the mechanical properties of the samples are given in Table 1.

Table 1. Basic mechanical properties of the tested hybrid MMCs.

\begin{tabular}{lllc}
\hline Sample & $\begin{array}{l}\text { Strength } \\
(\mathbf{M P a})\end{array}$ & $\begin{array}{l}\text { Hardness } \\
\text { (HRC) }\end{array}$ & $\begin{array}{l}\text { Toughness } \\
(\mathbf{J} / \mathbf{m} 2)\end{array}$ \\
\hline $\begin{array}{l}\mathrm{A} 359 / 2 \% \mathrm{~B}_{4} \mathrm{C} \\
/ 2 \% \mathrm{Al}_{2} \mathrm{O}_{3}\end{array}$ & 112.6 & 52.5 & 10.6 \\
\hline
\end{tabular}

The experimental work is performed on CNC lathe SPRINT 16TC made by BATLIBOI (Figure 2). Rotational speed was selected as a variable parameter in the range of $200 \mathrm{rpm}$ to $600 \mathrm{rpm}$. The reason behind the selection of this range is obtained from the pilot runs. The rotational speed out of the range (lower than 200 rpm and higher than $600 \mathrm{rpm}$ ) was significantly affected the surface topography of the machined surface and it increases the surface defects like tool marks, chattering etc. So that in the present work, the rotational speed of the workpiece was kept $200 \mathrm{rpm}, 400 \mathrm{rpm}$ and $600 \mathrm{rpm}$ for turning processes. The effect of rotational speed on surface characterization is also observed. The other process parameters of the machining process are fixed. Table 2 shows the technological conditions of turning in CNC lathe. The experiments are conducted at a given set of rotational speed, and three separate surfaces are created for each type of experimental run. The diameter of the workpiece samples was taken $20 \mathrm{~mm}$.

The elements of surface integrity such as roughness parameters (Ra, Rq, Rz), 3D surface visualization, surface topography, are discussed to understand the behaviour of the machined surface.

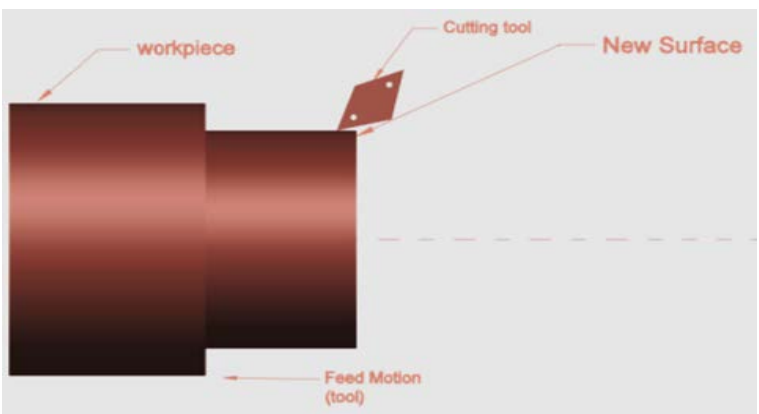

Figure 1. Cutting mechanisms in turning on CNC lathe

\section{Result and Discussion}

The turning process at three different speeds was successfully performed on the hybrid MMC workpiece. Figure 3 shows the surface created by turning processes. In visual observation, the surface texture of CNC lathe samples is shiny and free from defects like porosity and voids. Tool marks in the form of cutting lines, but no specific pattern is observed. These cutting lines are found significantly low when increasing the rotational speed.

Table 2. Technological conditions of turning operation

\begin{tabular}{ll}
\hline Parameters & Values \\
\hline Number of rotation (rpm) & $200,400,600$ \\
\hline Workpiece diameter (mm) & 20 \\
\hline Depth of cut (mm) & 0.2 \\
\hline Feed rate (mm/rev) & 0.050 \\
\hline Coolant type & SAE20W40 \\
\hline Tool insert & Coated Carbide \\
\hline Tool type & TNMG (Kyocera) \\
\hline
\end{tabular}

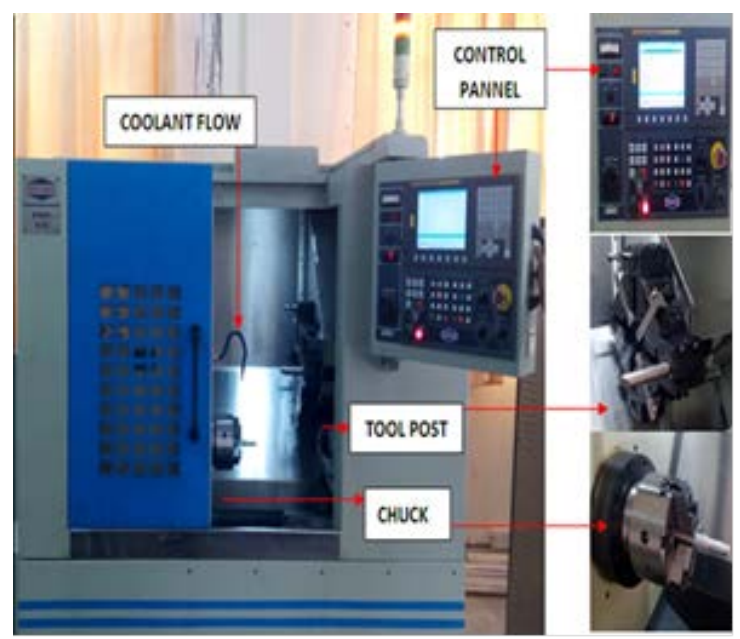

Figure 2. Sprint 16 TC CNC lathe machine 
The surface roughness report was generated for each turned surface using an optical profilometer. ISO 4287 standard has been applied to measure the roughness parameters along ten parallel lines on the circumferential surface of the cylindrical workpiece. The specifications of optical profilometer are as follows: Noise filter cut-off A similar pattern has been observed for other roughness

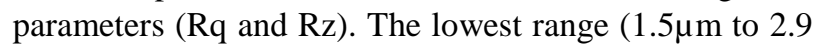
$\mu \mathrm{m})$ of average surface finish ( $\mathrm{Ra}$ ) has been observed in the turning process. Improved surface finishing at higher rotational speed is attributed to the reduction in built-up edge (BUE) formation of cutting insert.

Micro proof FRT optical profilometer is also used to capture the surfaces produced by the turning process. Figure 4 shows the $2 \mathrm{D}$ and $3 \mathrm{D}$ visualization of the machined surface created by CNC lathe at a given set of rotational speeds.

At a glance, it is challenging to differentiate all three surfaces which are similar in appearance. However, some of the observations are found on which they differ to each other. Images show the perfectly rolled surface and free from defects like porosity, voids or cracks. The surface texture shows the repetitive tool marks in the direction of feed and along the cutting direction. At the lower rotational speed (Figure 4 (a)), the tool marks are observed approximately parallel to each other. However, the small scale of the micro-pores appears on the surface. It is attributed to the effect of high thermal energy and mechanical stresses per unit time per unit area of the circumferential length due to which the formation of the larger built-up edge of tool insert is found during turning. At this stage, the tendency of dislodgment of reinforcement particles from the machined surface is increased and creates small-scale voids and porosity. At the medium range of rotational speed (400 rpm) shown in Figure 4 (b).

It is observed the undulation on the surface, and tools
$8 \mu \mathrm{m}$, evaluation length $7.5 \mathrm{~mm}$, sampling length $2.5 \mathrm{~mm}$, cut-off wavelength $2.5 \mu \mathrm{m}$ and the number of cut-offs 3 . Three parameters of roughness $\mathrm{Ra}, \mathrm{Rq}$, and $\mathrm{Rz}$ are measured, and their values are given in Table 3 . It is observed from the values that a better surface finishing can be found at an increasing trend of rotational speed. marks are slightly inclined. However, due to high contact stresses and heat, the surface porosity decreases. At higher rotational speed the formation of the built-up edge is reduced which makes the smooth surface as shown in Figure 4 (c).

Surface topography of all the machined surfaces is studied by images captured by OLYMPUS Lext OLS 3100 laser confocal microscope. Figure 5 shows the 2D and 3D surface topographical images of CNC lathe machined surfaces. The images revealed a flat surface full of repetitive cutting marks parallel to each other and along the direction of cutting. There are no significant topographical differences are varying rotational speed. At each set of rotational speed, approximately similar surface with few peaks and valleys are observed.

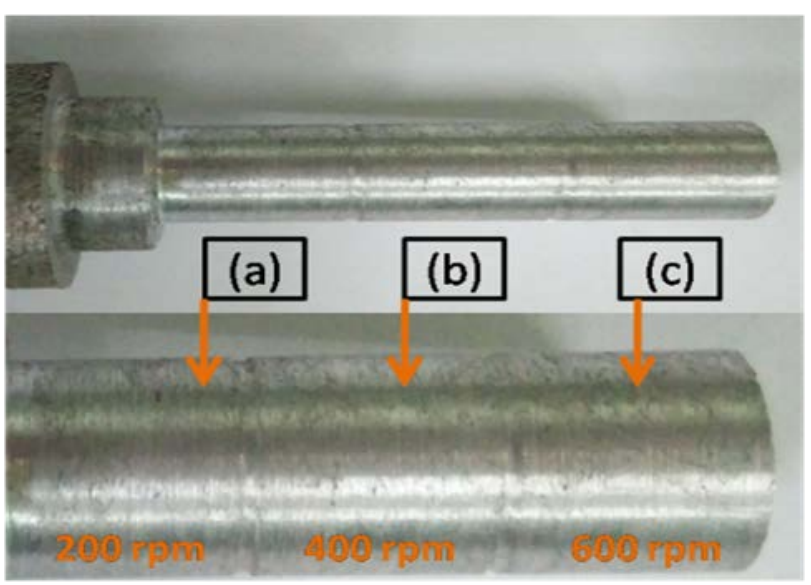

Figure 3. Machined samples of CNC lathe

Table 3. Surface Roughness report

\begin{tabular}{|c|c|c|c|c|c|c|c|c|c|c|}
\hline & \multirow{2}{*}{$\begin{array}{l}\text { Rotational } \\
\text { speed } \rightarrow\end{array} \rightarrow$} & \multicolumn{3}{|c|}{200 rpm } & \multicolumn{3}{|c|}{400 rpm } & \multicolumn{3}{|c|}{$600 \mathrm{rpm}$} \\
\hline & & $\mathbf{R a}$ & $\mathbf{R q}$ & $\mathbf{R z}$ & $\mathbf{R a}$ & $\mathbf{R q}$ & $\mathbf{R z}$ & $\mathbf{R a}$ & $\mathbf{R q}$ & $\mathbf{R z}$ \\
\hline \multirow{11}{*}{ 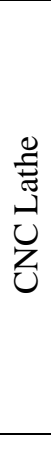 } & 1 & 2.463 & 2.958 & 14.671 & 1.870 & 2.342 & 13.638 & 1.602 & 1.991 & 11.428 \\
\hline & 2 & 2.240 & 2.894 & 17.184 & 1.873 & 2.301 & 12.925 & 1.645 & 2.090 & 13.641 \\
\hline & 3 & 2.432 & 3.242 & 19.357 & 1.524 & 1.948 & 12.368 & 1.577 & 1.973 & 13.282 \\
\hline & 4 & 2.619 & 3.394 & 22.213 & 1.856 & 2.232 & 12.474 & 1.510 & 1.887 & 12.491 \\
\hline & 5 & 2.658 & 3.332 & 17.406 & 1.906 & 2.276 & 11.527 & 1.530 & 1.922 & 12.034 \\
\hline & 6 & 3.011 & 3.632 & 17.807 & 2.023 & 2.604 & 15.206 & 1.723 & 2.118 & 10.670 \\
\hline & 7 & 2.755 & 3.458 & 18.334 & 2.262 & 2.822 & 17.049 & 1.633 & 2.034 & 12.162 \\
\hline & 8 & 2.693 & 3.481 & 20.387 & 2.267 & 2.806 & 14.652 & 1.637 & 2.012 & 10.818 \\
\hline & 9 & 2.964 & 3.699 & 22.391 & 2.122 & 2.660 & 13.904 & 1.538 & 1.919 & 11.132 \\
\hline & 10 & 2.869 & 4.614 & 30.524 & 2.277 & 2.985 & 16.183 & 1.644 & 2.077 & 15.296 \\
\hline & Avg & 2.6704 & 3.4704 & 20.0274 & 1.998 & 2.4976 & 13.9926 & 1.603 & 2.0023 & 12.2954 \\
\hline
\end{tabular}



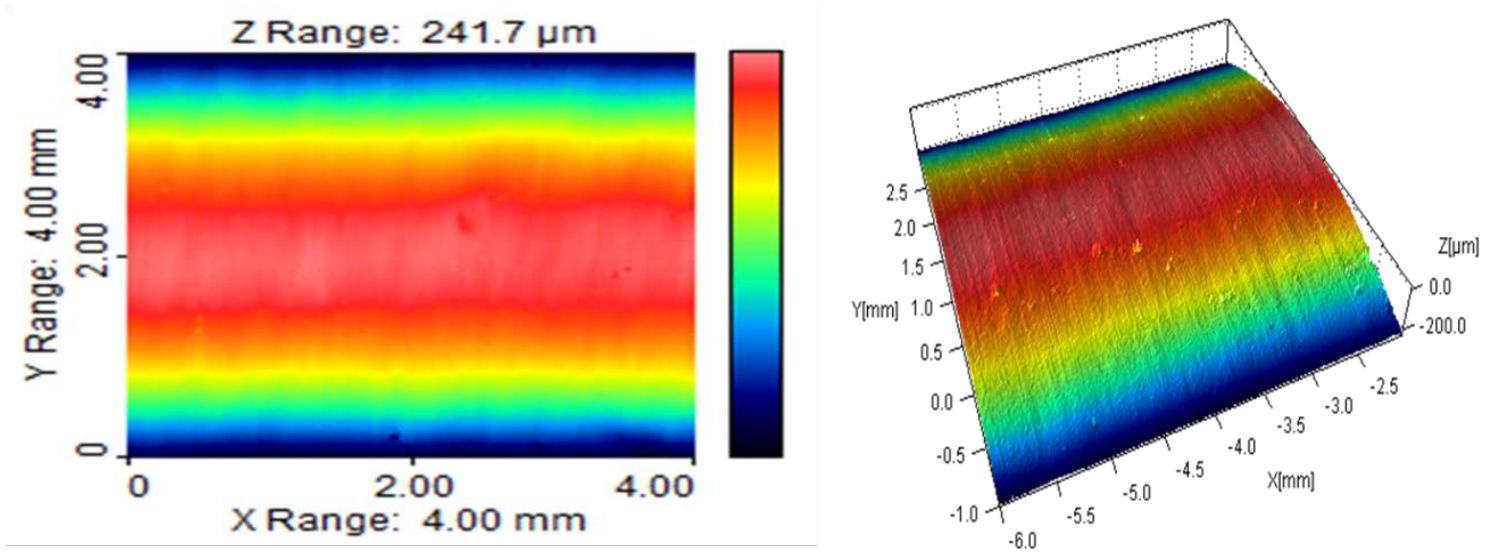

(a)
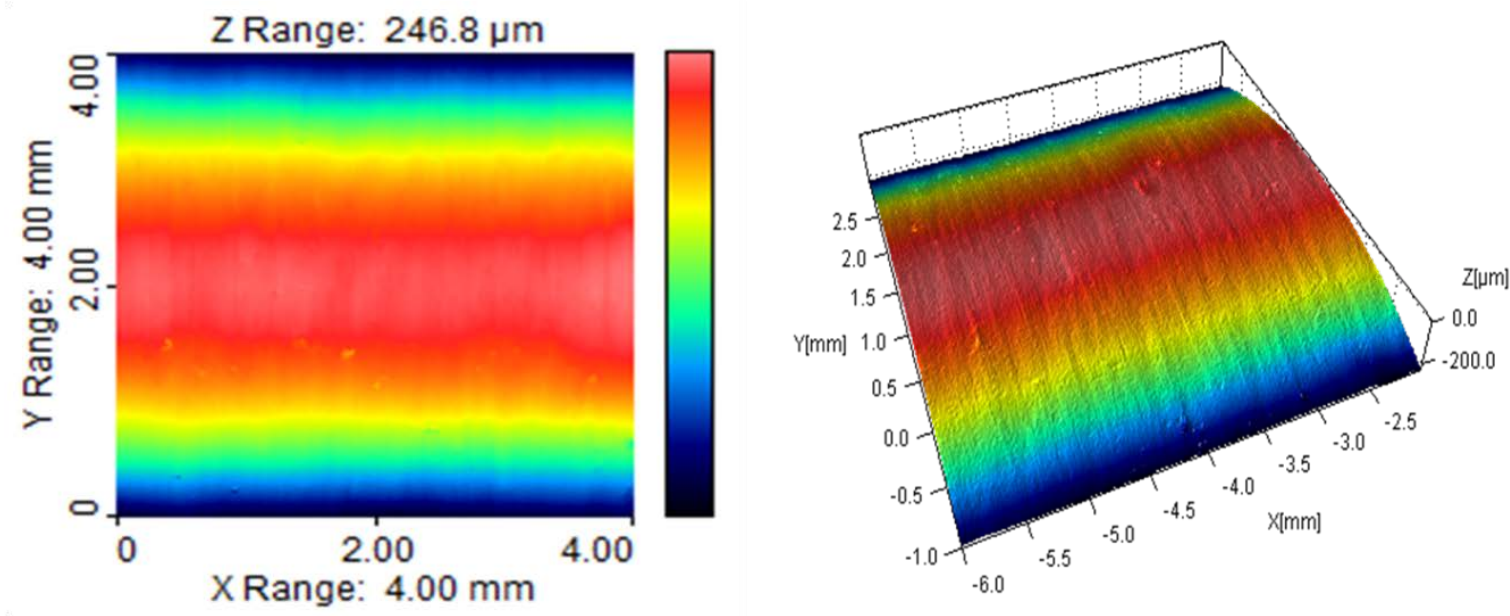

(b)
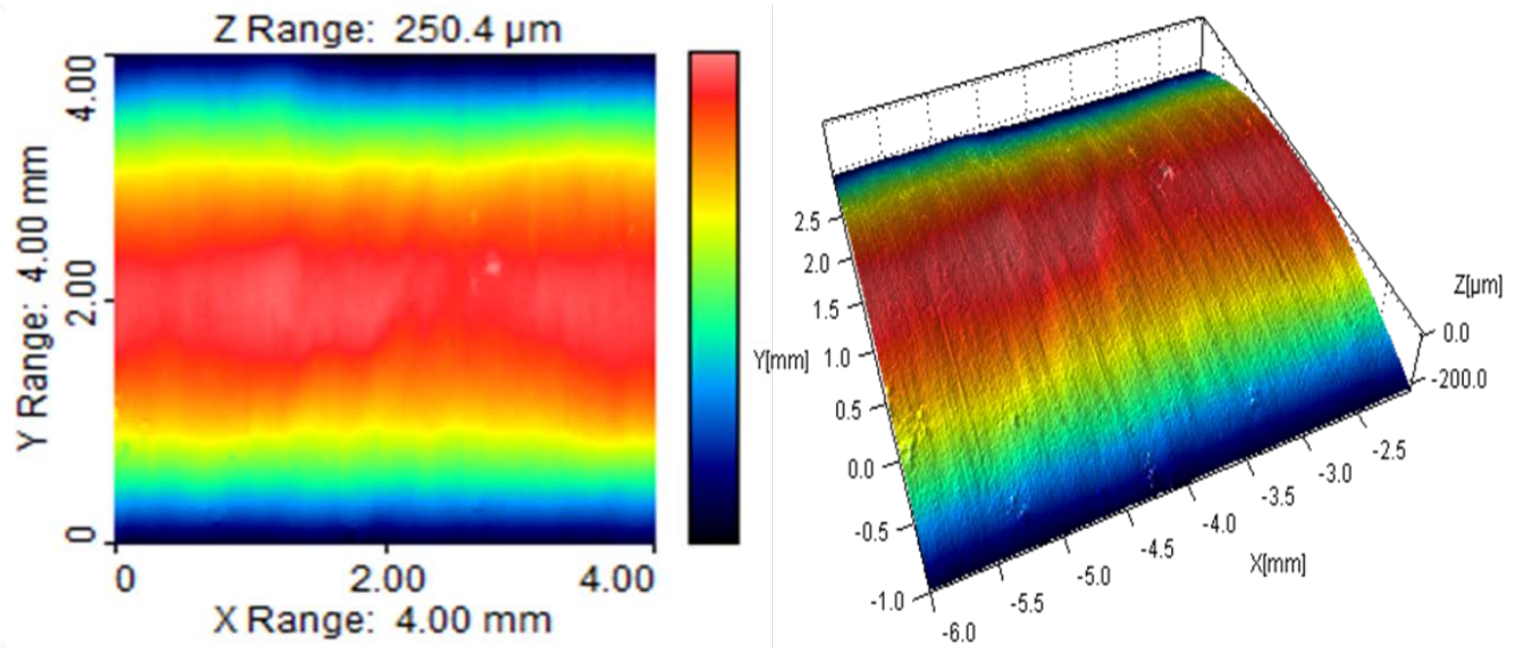

(c)

Figure 4. Surface visualisation produced by CNC lathe at (a) $200 \mathrm{rpm}$ (b) $400 \mathrm{rpm}$ (c) $600 \mathrm{rpm}$ 

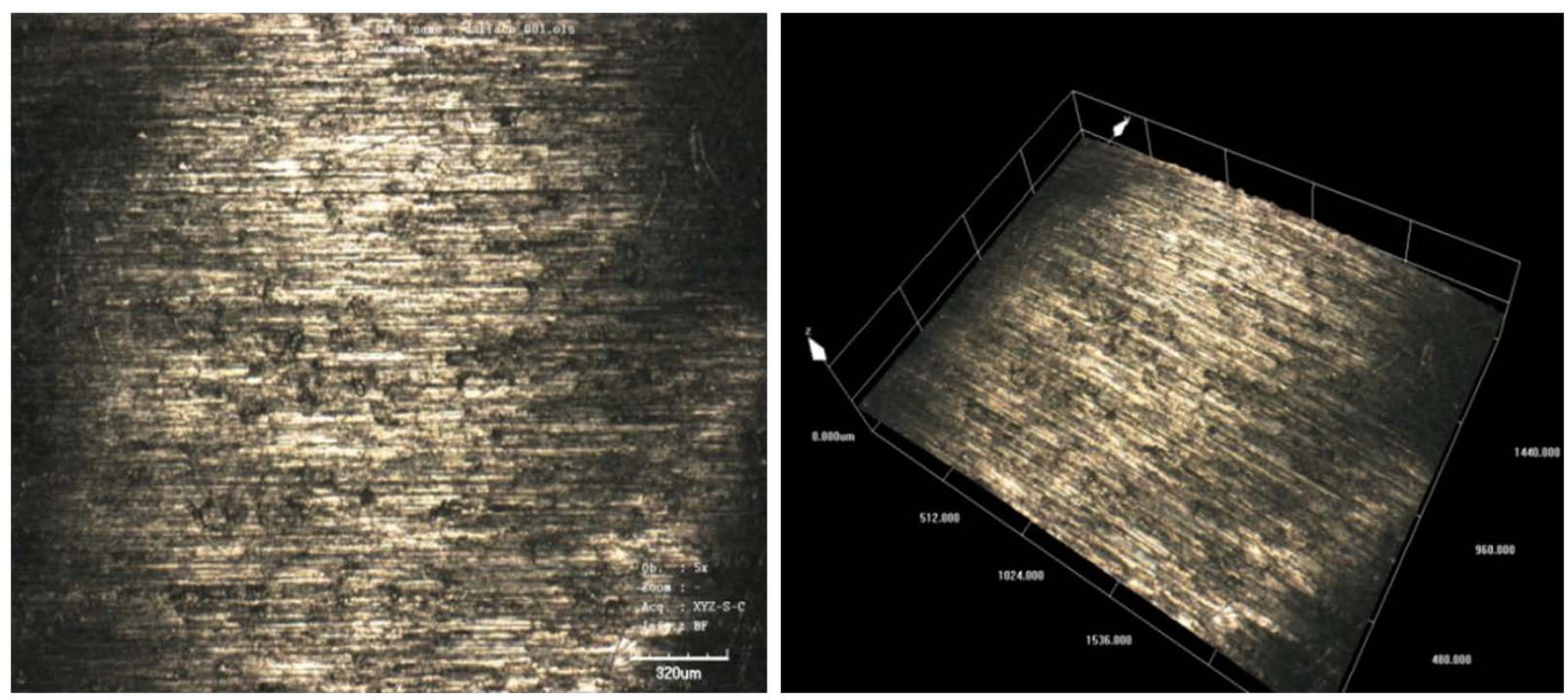

(a)
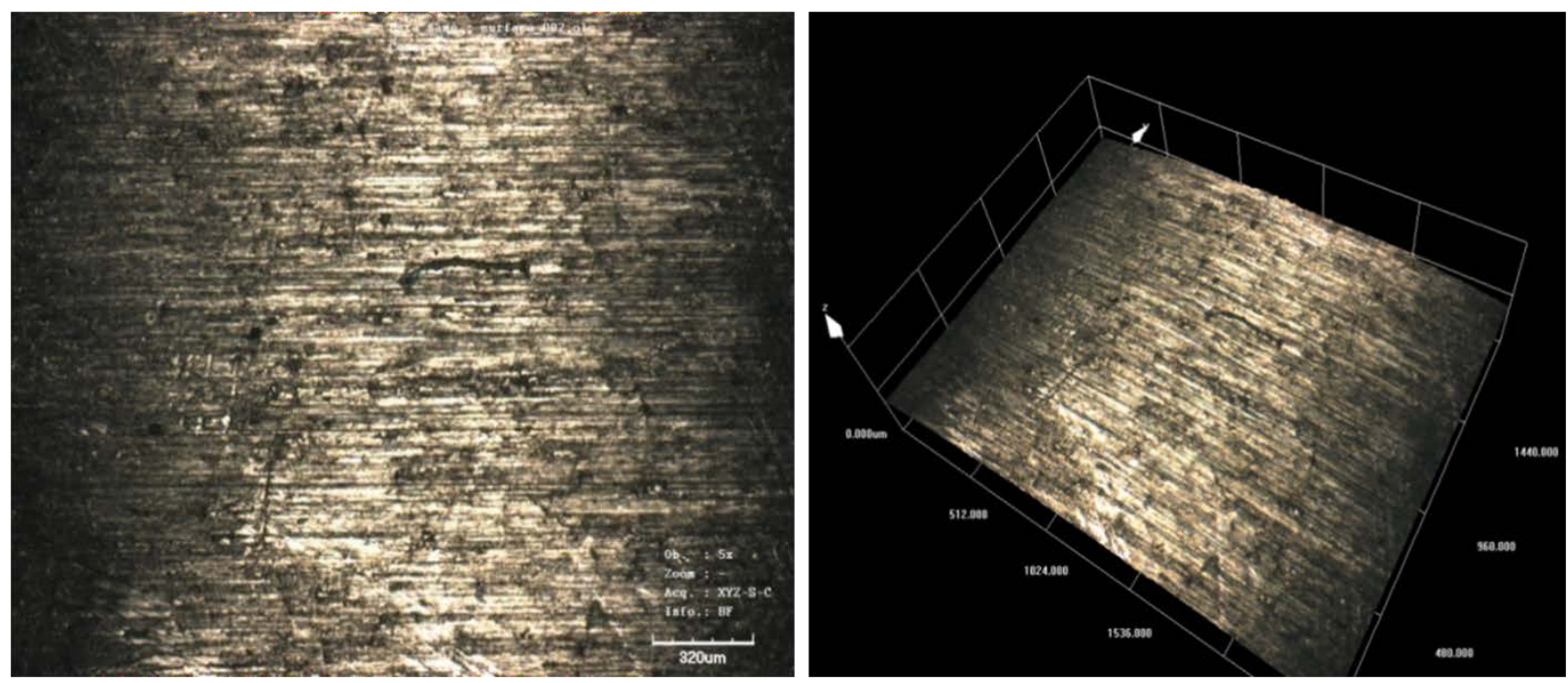

(b)
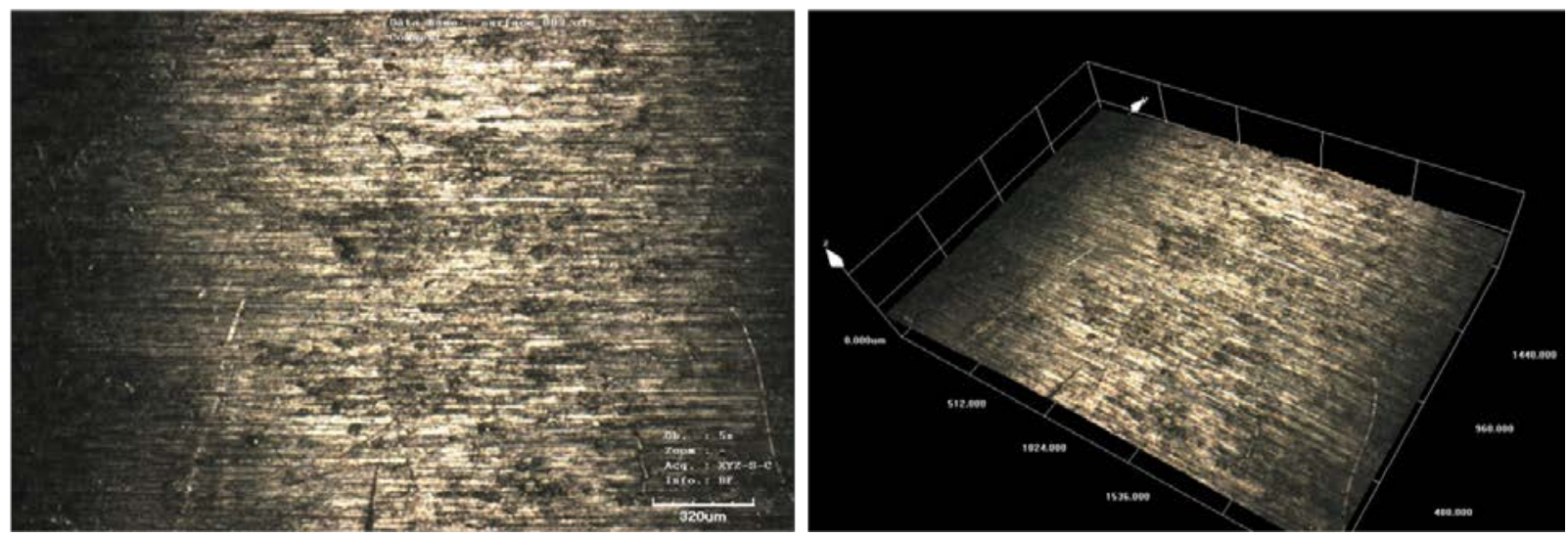

(C)

Figure 5. Surface topography by CNC Lathe surfaces (a) 200 rpm, (b) 400 rpm, (c) 600 rpm 


\section{Conclusion}

The present work highlights the outcome of turning operation on $\mathrm{A} 359 / 2 \% \mathrm{~B}_{4} \mathrm{C} / 2 \% \mathrm{Al}_{2} \mathrm{O}_{3}$ by $\mathrm{CNC}$ lathe (SPRINT 16TC BATLIBOI). The study includes the measurement of surface roughness parameters namely $\mathrm{Ra}, \mathrm{Rq}$ and $\mathrm{Rz}$ and the topographical study of the turned surface by 3D surface visualization images and topographical images. Based on observations the following conclusion has suggested:

1. The range of surface roughness value lies between $1.5 \mu \mathrm{m}$ to $2.9 \mu \mathrm{m}$ during the turning operation at varying rotational speed from $200 \mathrm{rpm}$ to $600 \mathrm{rpm}$. The Improved surface finishing at higher rotational speed is observed which is attributed to the reduction in built-up edge (BUE) formation of cutting insert.

2. 3D surface images show the perfectly rolled and free from defects like porosity, voids or cracks. The surface texture shows the repetitive tool marks in the direction of feed and along the cutting direction. 2D and 3D surface topographical images revealed a flat surface full of repetitive cutting marks parallel to each other and along the direction of cutting. There are no significant topographical differences are varying rotational speed.

3. At the lower rotational speed, the tool marks are observed approximately parallel to each other, while at higher rotational speed the formation of the built-up edge is reduced which makes the smooth surface. The small scale of the micropores appears on the surface. It is attributed to the effect of high thermal energy and mechanical stresses per unit time per unit area of the circumferential length. At this stage, the tendency of dislodgment of reinforcement particles from the machined surface is increased and creates small-scale voids and porosity.

\section{Declaration of conflicting interest}

The author(s) declared no potential conflicts of interest concerning the research, authorship, and/or publication of this article.

\section{Acknowledgement}

The author(s) received no financial support for the research, authorship, and/or publication of this article.

\section{References}

1) S. P. Dwivedi, M. Maurya, N. K. Maurya, A. K. Srivastava, S. Sharma, A. Saxena. Utilization of Groundnut Shell as Reinforcement in Development of Aluminum Based Composite to Reduce Environment Pollution: a review. EVERGREEN Joint Journal of Novel Carbon Resource Sciences \& Green Asia Strategy. 7,15, (2020).

2) M. Maurya, S. Kumar, V. Bajpai and N. K. Maurya, Process parameters, development and applications of stir cast composite: A review, Materials Testing. 62,196 (2020).

3) Manish Maurya, Sudhir Kumar, and Vivek Bajpai, Assessment of the mechanical properties of aluminium metal matrix composite: A review, Journal of Reinforced Plastics and Composites, 38,267 (2019)

4) Sashi Prakash Dwivedi, Nagendra Kumar Maurya and Manish Maurya, Assessment of hardness on AA 2014/Eggshell composite produced via stir casting method. Evergreen Joint Journal of Novel Carbon Resource Sciences \& Green Asia Strategy, 6, 285, (2019).

5) Maurya, N.K., Maurya, M., Srivastava, A.K., Dwivedi, S.P., Kumar, A., Chauhan, S. Investigation of mechanical properties of $\mathrm{Al} 6061 / \mathrm{SiC}$ composite prepared through stir casting technique. Materials Today: Proceedings. (2019).https://doi.org/10.1016/j.matpr.2019.09. 003.

6) Manish Maurya, Nagendra Kumar Maurya and Vivek Bajpai, Effect of SiC reinforced particle parameters in the development of aluminium based metal matrix composite. Evergreen Joint Journal of Novel Carbon Resource Sciences \& Green Asia Strategy, 6, 200 (2019)

7) Nag A, Srivastava AK, Dixit AR, Mandal A, Das AK, Surface integrity analysis of wire-EDM on in-situ hybrid composite A359/Al2O3/B4C, Materials today Proceedings, 5, 24632, (2018).

8) S. P. Dwivedi, N. K. Maurya, A. K. Srivastava, M. Maurya, Microstructure and mechanical properties of Al6061/Al2O3/flyash composite fabricated through stir casting, Annales de Chimie-Science des Materiaux 43, 341-346 (2019)

9) I. Narasimha Murthy, D. Venkata Rao, J.Babu Rao, Microstructure and mechanical properties of aluminium-fly ash nanocomposites made by ultrasonic method, Materials \& Design, 35, 55 (2012).

10) S.T. Mavhungu, E. T. A. Kinlabi, M. A. Onitiri, F.M. Varachia. AMC for industrial use: Advances and Trends. Procedia Manufacturing, 7,178, (2016).

11) Rajesh Kumar Bhushan, Sudhir Kumar, Optimization of porosity of $7075 \mathrm{Al}$ alloy $10 \% \mathrm{SiC}$ composite produced by stir casting process through Taguchi method. Int. J. Materials Engineering Innovation, 1,116 (2009).

12) J. Hashim, L. Looney, M.S.J. Hashmi. Metal matrix composites: production by the stir casting method. Journal of Materials Processing Technology, 92,1(1999).

13) Srivastava. A Dixit. A.R., Tiwari. S, A Review on Fabrication and Characterization of Aluminium Metal, Matrix Composite (AMMC), International Journal of Advanced Research and Innovation, 2, 516, (2014). 
14) Nag A, Srivastava AK, Dixit AR, Chattopadhyaya $S$, Mandal A, P. Hlavacek, D. Klichova M. Zelenak, S. Hloch, Influence of Abrasive Water Jet Turning Parameters on Variation of Diameter of Hybrid Metal Matrix Composite. In: Singh M., Kushvah B., Seth G., Prakash J. (eds) Applications of Fluid Dynamics. Lecture Notes in Mechanical Engineering. Springer, Singapore,(2018). https://doi.org/10.1007/978-981-10-5329-0_36.

15) Ashish Kumar Srivastava, Statistical optimization of wire-EDM during the processing of hybrid MMC, International Journal of Mechanical and Production Engineering Research and Development, 8, 783 (2018).

16) AK Srivastava, AR Dixit, S Tiwari, A Review on the intensification of metal matrix composites and its non-conventional machining, Science and Engineering of composite materials, (2016).DOI: https:// doi. Org/ 10.1515/secm-2015-0287.

17) Ashish Kumar Srivastava, S.P. Dwivedi, Abhishek Sharma, Nagendra Kumar Maurya, Prabhat Ranjan, International Journal of Engineering \& Technology, 7, 434 (2018).

18) Garg H. K., Verma Ketan, Manna Alakesh and Kumar Rajesh, International Journal of Latest Research in Science and Technology, 1, 36, (2012).

19) Sasimurugan T. and Palanikumar K., Analysis of the machining characteristics on surface roughness of a hybrid aluminium metal matrix composite (Al6061-SiC-Al2O3), Journal of Minerals \& Materials Characterization \& Engineering, 10, 1213 (2011).

20) Baki, N., Reddy, A.C., Rao, T.B., Selection of optimal process parameters in wire electrical discharge turning while machining TI-6AL-4V ALLOY, International Conference on Advanced Materials and Manufacturing Technologies (AMMT) (2014).

21) Boujelbene, M., Bayraktar, E., Tebni, W., Salem, S. Ben, 2009, Influence of machining parameters on the surface integrity in electrical discharge machining. Arch. Mater. Sci. Eng. 37, 110.

22) Das, A.K., Kumar, P., Sethi, A., Singh, P.K., Hussain, M., 2016. Influence of process parameters on the surface integrity of micro-holes of SS304 obtained by micro-EDM. J. Brazilian Soc. Mech. Sci. Eng. 38, 2029.

23) Davim, J.P., 2010. Surface integrity in machining, e-ISBN 978-1-84882-874-2, DOI 10.1007/978-1-84882-874-2, Springer. (2010)

24) Grzesik, W., Rech, J., Wanat, T., Surface integrity of hardened steel parts in hybrid machining operations. J. Achiev. Mater. Manuf. Eng. 18, 367 (2006).

25) Srivastava, A.K., Nag, A., Dixit, A.R., Tiwari, S., Scucka, J., Zelenak, M., Hloch, S., Hlavacek, P., Surface integrity in tangential turning of hybrid
MMC A359/B $4 \mathrm{C} / \mathrm{Al}_{2} \mathrm{O}_{3}$ by abrasive water jet. $J$. Manuf. Process. 28, 11 (2017). 